Aim of the study: A number of observations have indicated that the immune system plays a significant role in patients with epithelial ovarian cancer (EOC). In cases of EOC, the prognostic significance of tumour infiltrating lymphocytes has not been clearly explained yet. The aim is to determine the phenotype and activation molecules of cytotoxic T cell and NK cell subpopulations and to compare their representation in malignant ascites and peripheral blood in patients with ovarian cancer.

Material and methods: Cytotoxic cells taken from blood samples of the cubital vein and malignant ascites were obtained from 53 patients with EOC. Their surface and activation characteristics were determined by means of a flow cytometer. Immunophenotype multiparametric analysis of peripheral blood lymphocytes (PBLs) and tumour infiltrating lymphocytes (TILS) was carried out.

Results: $\mathrm{CD}^{+} \mathrm{T}$ lymphocytes were the main population of TILs (75.9\%) and PBLs $(70.9 \%)$. The number of activating $T$ cells was significantly higher in TILs: $\mathrm{CD}^{+} / 69^{+} 6.7 \%$ vs $0.8 \%(p<0.001)$. The representation of $\left(\mathrm{CD}^{-} / 16^{+} 56^{+}\right)$NK cells in TILs was significantly higher: $11.0 \%$ vs. $5.6 \%$ $(p=0.041)$; likewise CD56 bright and CD$56^{\text {bright }}$ from $\mathrm{CD} 56^{+}$cells were higher in TILs (both $p<0.001$ ). The activation receptor NKG2D was present in $45.1 \%$ of TILs vs. $32.3 \%$ of PBLs ( $p=0.034$ ), but we did not find a significant difference in the numbers of CD56+/NK-

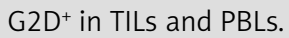

Conclusions: These results prove that the characteristics and intensity of anti-tumour responses are different in compared compartments (ascites/ PBLS). The knowledge of phenotype and functions of effector cells is the basic precondition for understanding the anti-tumour immune response.

Key words: tumour-infiltrating lymphocytes, NK cells, NKG2D, flow cytometry, ovarian cancer.

Contemp Oncol (Pozn) 2015; 19 (4): 290-299 DOI: $10.5114 /$ wo.2015.54388

\section{Comparative study of various subpopulations of cytotoxic cells in blood and ascites from patients with ovarian carcinoma}

\begin{abstract}
Sarka Lukesova ${ }^{1}$, Vladimira Vroblova ${ }^{2}$, Jindrich Tosner ${ }^{3}$, Jindrich Kopecky ${ }^{4}$, Iva Sedlakova ${ }^{3}$, Eva Čermáková5, Doris Vokurkova ${ }^{3}$, Otakar Kopecky ${ }^{1,6}$
\end{abstract}

'Department of Oncology, District Hospital Nachod, Department of Clinical Microbiology, Faculty of Medicine, Charles University in Prague, Hradec Kralove, Czech Republic 2Department of Clinical Immunology and Allergology, University Hospital in Hradec Kralove, Czech Republic

${ }^{3}$ Department of Obsterics, University Hospital in Hradec Kralove; Faculty of Medicine, Charles University in Prague, Hradec Kralove, Czech Republic

${ }^{4}$ Department of Oncology and Radiotherapy, University Hospital in Hradec Kralove; Faculty of Medicine, Charles University in Prague, Hradec Kralove, Czech Republic ${ }^{5}$ Department of Medical Biophysics, Computer Technology Center; Faculty of Medicine, Charles University in Prague, Hradec Kralove, Czech Republic

${ }^{6}$ Department of Dentistry, Faculty of Medicine, Charles University in Prague, Hradec Kralove, Czech Republic

\section{Introduction}

Epithelial ovarian cancer is the fifth leading cause of cancer-related death in women [1]. This disease is manifested by vague clinical symptoms and the fact that specific diagnostic molecular markers are missing. Most patients are diagnosed at an advanced stage with limited therapeutic options. Chemotherapeutic strategies usually achieve only a partial response, and therefore it is necessary to seek other therapeutic options. Immunotherapy of ovarian tumours is considered one of the possible modalities for use in a primary or consolidation approach [2].

The central effector role of $\mathrm{T}$ cytotoxic lymphocytes and natural killer (NK) cells in an anti-tumour response is well known [3-6]. However, objective findings indicate that tumour cells grow in the presence of mononuclear cell infiltration. These studies suggest that tumour-associated lymphocytes are not capable of evoking an effective immune response [7]. It is clear that the plasticity of tumour cells in changing the expression of cell-surface molecules, for example downregulation of human leukocyte antigen (HLA) molecules, or low density or even absence of tumour-specific antigens, is an important cause of the failure of the anti-tumour response. Cytotoxicity of $T$ cells depends on the expression of HLA class I molecules. These properties mediate a negative effect on immune surveillance. Tumours can also fail to present their antigens owing to defects in the intracellular peptide transporter TAP or in the components of immunoproteasome genes [8-10]. Besides the insufficient tumour immune response due to alteration of the processing cascade of a specific antigen, a great number of studies document the direct suppressive effect of the tumour environment on cytotoxic lymphocyte effectiveness [11]. Although cancer stroma lymphocyte infiltrations are present in the majority of human neoplasms, these lymphocytes are mostly functionally defective, incompletely activated and anergic [3]. Through the downregulation of activation and proliferation of tumour-specific cytotoxic T lymphocytes and NK cells, cancers are able to overcome immune surveillance. Incompletely activated tumour infiltrating lymphocytes (TILS) and cancer cells produce chemokines that are chemoattractants for other leu- 
kocytes and regulate their migration into tumour stroma. The prognostic significance of TILs has been recently recognized in various neoplasms. In epithelial ovarian cancer, most of the studies performed in paraffin-embedded tissue have shown that the presence of TILs is an independent favourable prognostic factor. Numerous investigators have reported that TILs obtained from patients with ovarian carcinoma contain activated cytotoxic $T$ lymphocytes and NK cells, which were subsequently ex vivo cultivated with a low concentration of IL-2. In these instances, the CD8 T cell, TcR positive and NK cell population expanded, and the cells exhibited primarily autologous tumour cell cytotoxicity $[4,12,13]$.

The presence of ascites in advanced stages of ovarian cancer offers a unique opportunity to obtain tumour-associated lymphocytes (TALS) directly from the site of a malignant process. There is still limited data about the prognostic significance of cytotoxic T cells and NK cell subtypes freshly isolated from a tumour or ascites $[17,18]$. But some studies show that TALs may play an important role in the immune response against tumours [17].

For the above reasons, we began to study prospectively the population of cytotoxic cells in ascites associated with epithelial ovarian cancer concomitantly with peripheral blood lymphocytes. Here, we present the results of a flow cytometric phenotype analysis of both cytotoxic $T$ cells and NK cell subtypes and their activation molecules in ascitic fluid and peripheral blood. Due to our better knowledge we have used a brighter spectrum of activation markers than before.

\section{Material and methods}

\section{Patients}

Ascites and peripheral blood were obtained from 53 patients with diagnosed ovarian cancer or patients undergoing surgery for suspected ovarian cancer prior to neo-adjuvant, adjuvant or palliative chemotherapy. The study was carried out between January 2006 and 2013 at the University Hospital Hradec Králové, Czech Republic. Inclusion in the study was confirmed after a histopathologic diagnosis of invasive epithelial ovarian carcinoma (Table 1). All patients gave their written informed consent prior to their participation in the study. The study was approved by the Institutional Review Committee. The median age of the patients was 64 (range 40-83). In 38 patients (71\%), a radical operation was performed, although only 11 of them (29\%) received neo-adjuvant chemotherapy. The most frequent tumour stage was FIGO IIIC (60\%); in our group there were only four patients (7\%) with metastatic disease. Most of the patients received at least one chemotherapy line; only 12 patients (22\%) did not start any chemotherapy due to their altered clinical performance. The most usual chemotherapy was based on paclitaxel and carboplatin; the other cytostatic agents used during therapy were topotecan, cisplatin and gemcitabine. The time to first progression (measured from time of diagnosis to relapse after the first line treatment and/or surgery) was 154 days (0-1711), and in 18 patients (34\%) no progression had occurred at follow-up. The median survival in our group was 1996 days (25-2563) and at the end of follow-up on $1^{\text {st }}$ January 2013, 22 (41\%) were still alive.

\section{Methods}

Heparinized test tubes were used to collect peripheral blood from the cubital vein. The malignant ascites were obtained via open surgery, laparoscopy or paracentesis before chemotherapy in tubes with a heparin solution in a final concentration of $25 \mathrm{U} / \mathrm{ml}$. The ascitic fluids were centrifuged at $1000 \mathrm{rpm}$ for 10 minutes at $4^{\circ} \mathrm{C}$. Isolated cells were twice washed and diluted to an approximate concentration of $5 \times 10^{5}$ cells. The samples were processed up to 2 hours after their sampling. Each time, $25 \mu$ of heparinized blood and cellular suspension were incubated for 20 minutes in the dark at room temperature with $10 \mu$ of diluted conjugated monoclonal antibodies (Immunotech and Beckman Coulter). The combinations were as follows: CD45-FITC/CD14-PE (for gating), CD3-FITC/CD16/56-PE/ CD19-PC5, CD45RO-FITC/CD45RA-PE/CD4-PC5, CD8-FITC/ DR-PE/CD3-PC5, CD69-FITC/CD25-PE/CD3-PC5, CD57-FITC/ TCR $\alpha \beta-P E / C D 8-P C 5$, CD8-PC5/CD56-PE/NKG2D-FITC and CD3-FITC/CD8-PC5/TCR $\gamma \delta$-PE. After lysing erythrocytes with a lysing solution ( $0.5 \mathrm{ml}$ of OptiLyse C, Beckman Coulter), a buffer was added with $0.5 \%$ foetal calf and $0.01 \%$ sodium azide. The measurement was carried out by means of a three-colour fluorescence Coulter Epics XL flow cytometer (the Coulter Company, Fullerton, USA). At least 5000 gated events were analysed. Subpopulations were measured as a percentage of the total number of CD45-positive cells (and the total number of CD3-positive cells). The expression of activation markers CD69, HLA-DR and CD25 molecules was assessed on gated CD3 positive cells by plotting CD4 or CD8 positive cells vs. the given activation markers. The evaluation of measured samples was carried out by means of CPX analysing software (Fig. 1). The results were calculated from the data of 53 patients suffering from EOC.

Statistical evaluation of the measured values was carried out by means of NCSS 2007 Statistica. The statistics were processed using standard methods for a statistical comparison of two groups. Normality value tests were unsuccessful in the evaluated cases; for this reason, the one-way ANOVA on ranks test was carried out to determine the level of statistical significance. The median was an indicator of the value position. Using Cox proportional-hazards regression, we observed the potential effect of acquired immunological parameters from ascitic fluid, both on the overall survival, and also on the length of time to first progression. Differences were considered significant at $p<0.05$.

\section{Results}

The phenotype of cytotoxic cells was determined by means of the three-colour immunofluorescence method, and their representation in peripheral blood (PB) and ascites was compared. The both compartments exhibited a dominant $\mathrm{CD}^{+} \mathrm{T}$ lymphocyte population. The number of $\mathrm{CD}^{+} / \mathrm{CD}^{2} 9^{+}$(activated) cells was significantly higher in ascites $(p<0.001)$. The CD8 $8^{+} T$ lymphocyte count was 
Table 1. Clinical and histopathological characteristics of patients with ovarian carcinoma

\begin{tabular}{|c|c|c|c|c|c|c|c|c|c|}
\hline $\begin{array}{l}\text { Patient } \\
\text { number }\end{array}$ & $\begin{array}{c}\text { Age } \\
\text { (years) }\end{array}$ & $\begin{array}{c}\text { FIGO } \\
\text { classification }\end{array}$ & Histology & Grade & $\begin{array}{l}\text { Radical } \\
\text { surgery } \\
\text { Yes/No }\end{array}$ & $\begin{array}{c}\text { Neoadjuvant } \\
\text { treatment } \\
\text { Yes/No }\end{array}$ & $\begin{array}{l}\text { Number of } \\
\text { treatment } \\
\text { lines }\end{array}$ & $\begin{array}{l}\text { Time to first } \\
\text { progression } \\
\text { (days) }\end{array}$ & $\begin{array}{c}\text { Overall } \\
\text { survival } \\
\text { (days) }\end{array}$ \\
\hline 1 & 60 & $\mathrm{IIIC}$ & serous & 1 & no & yes & 3 & 343 & 986 \\
\hline 2 & 56 & IIIC & serous & 2 & yes & yes & 2 & 0 & 2315 \\
\hline 3 & 53 & $\mathrm{IIIC}$ & serous & 3 & yes & no & 5 & 719 & 2267 \\
\hline 4 & 62 & IIIC & serous & 3 & yes & yes & 3 & 993 & 1367 \\
\hline 5 & 51 & IV & serous & 3 & no & no & 1 & no & 134 \\
\hline 6 & 55 & IIIC & serous & 3 & yes & yes & 5 & 640 & 2374 \\
\hline 7 & 47 & IIC & serous & 3 & yes & no & 5 & 1211 & 2395 \\
\hline 8 & 69 & IIIC & serous & 3 & no & no & 2 & 217 & 754 \\
\hline 9 & 62 & IIIC & serous & 2 & yes & no & 0 & 0 & 2228 \\
\hline 10 & 65 & IIIC & serous & 3 & yes & no & 4 & 489 & 2093 \\
\hline 11 & 61 & $\mathrm{IIIC}$ & serous & 3 & yes & yes & 1 & 0 & 2262 \\
\hline 12 & 70 & $\mathrm{IIIC}$ & serous & 3 & yes & yes & 5 & 589 & 1321 \\
\hline 13 & 74 & $\mid \mathrm{A}$ & unodifferentiated & 2 & yes & no & 0 & 0 & 2492 \\
\hline 14 & 69 & IIIC & endometrioid & 2 & yes & yes & 2 & 452 & 615 \\
\hline 15 & 69 & IC & endometrioid & 3 & yes & no & 1 & 0 & 2190 \\
\hline 16 & 71 & IV & serous & 3 & no & no & 1 & no & 89 \\
\hline 17 & 64 & $\mathrm{IIIC}$ & serous & 3 & yes & no & 2 & 580 & 963 \\
\hline 18 & 82 & IIIC & endometrioid & 3 & yes & no & 1 & 0 & 338 \\
\hline 19 & 64 & IIIC & serous & 3 & yes & yes & 2 & 450 & 529 \\
\hline 20 & 55 & $\| \mathrm{A}$ & endometrioid & 2 & yes & no & 5 & 938 & 1222 \\
\hline 21 & 51 & IIIC & undifferentiated & 3 & yes & no & 2 & 0 & 2169 \\
\hline 22 & 78 & IIIB & serous & 3 & no & no & 1 & NO & 267 \\
\hline 23 & 65 & $\mathrm{IIIC}$ & serous & 3 & yes & no & 1 & 0 & 2116 \\
\hline 24 & 83 & IIIC & endometrioid & 2 & no & no & 2 & 377 & 583 \\
\hline 25 & 40 & IIIA & serous & 1 & yes & no & 1 & 0 & 2499 \\
\hline 26 & 64 & IIIC & serous & 1 & yes & no & 1 & 0 & 2190 \\
\hline 27 & 51 & IV & serous & 3 & yes & no & 1 & 0 & 2563 \\
\hline 28 & 71 & IIIC & serous & 3 & yes & yes & 4 & 854 & 2041 \\
\hline 29 & 57 & $\mathrm{IB}$ & endometrioid & 2 & yes & no & 1 & 0 & 2116 \\
\hline 30 & 74 & IIIA & serous & 3 & no & no & 4 & 102 & 2081 \\
\hline 31 & 67 & $I I I C$ & serous & 3 & no & no & 0 & no & 28 \\
\hline 32 & 79 & $\mathrm{IIIC}$ & serous & 3 & no & no & 0 & no & 63 \\
\hline 33 & 77 & IIIC & endometrioid & 2 & no & no & 0 & no & 54 \\
\hline 34 & 56 & IIIA & serous & 3 & yes & no & 5 & 703 & 1996 \\
\hline 35 & 72 & $\mathrm{IIIC}$ & undifferentiated & 3 & no & no & 0 & 114 & 707 \\
\hline 36 & 61 & IIIC & serous & 3 & yes & no & 0 & 0 & 2224 \\
\hline 37 & 71 & IIIC & mucinous & 3 & yes & no & 3 & 185 & 593 \\
\hline 38 & 59 & la & mucinous & 2 & yes & no & 3 & 279 & 2268 \\
\hline 39 & 56 & $\mathrm{IIIB}$ & serous & 3 & yes & no & 0 & 0 & 2002 \\
\hline 40 & 54 & IIIA & endometrioid & 3 & yes & no & 1 & 428 & 1761 \\
\hline 41 & 72 & IIIA & undifferentiated & 3 & yes & no & 1 & 0 & 2122 \\
\hline 42 & 61 & IIIB & undifferentiated & 3 & yes & no & 0 & 131 & 907 \\
\hline 43 & 74 & $\mathrm{IIIC}$ & serous & 3 & yes & no & 1 & 0 & 2190 \\
\hline 44 & 66 & IIIB & endometrioid & 2 & yes & yes & 5 & 440 & 1596 \\
\hline 45 & 72 & $\mathrm{IIIb}$ & mucinous & 3 & no & no & 0 & no & 25 \\
\hline 46 & 68 & $\mathrm{IIIC}$ & undifferentiated & 3 & no & no & 0 & no & 53 \\
\hline 47 & 48 & $\| \mathrm{II}$ & serous & 2 & yes & no & 1 & 0 & 2105 \\
\hline 48 & 66 & $\mathrm{IIIC}$ & serous & 2 & yes & no & 1 & 0 & 2122 \\
\hline 49 & 72 & IIIC & endometrioid & 3 & yes & yes & 2 & 259 & 589 \\
\hline 50 & 61 & IV & serous & 3 & no & no & 0 & no & 130 \\
\hline 51 & 66 & $\mathrm{IIIC}$ & serous & 2 & no & no & 0 & no & 53 \\
\hline 52 & 62 & $\mathrm{IIIC}$ & serous & 3 & yes & no & 1 & 1711 & 2240 \\
\hline 53 & 59 & $\mathrm{IIIC}$ & serous & 3 & yes & yes & 3 & 154 & 2292 \\
\hline
\end{tabular}


Table 2. Phenotyping analysis of CD45 positive cells from peripheral blood and malignant ascites from 53 patients with ovarian cancer

\begin{tabular}{|c|c|c|c|}
\hline Cell population & $\begin{array}{l}\text { Peripheral blood } \\
\text { (\%) }\end{array}$ & $\begin{array}{c}\text { Ascites } \\
(\%)\end{array}$ & $p$ \\
\hline $\mathrm{CD}^{+}$ & 70.9 (61.8-75.1) & $75.0(71.1-82.4)$ & 0.097 \\
\hline $\mathrm{CD}^{+} / \mathrm{CD} 69^{+}$ & $0.8(0.2-2.1)$ & $6.7(4.5-15.2)$ & $<0.001$ \\
\hline $\mathrm{CD}^{+} / \mathrm{CD}^{2} 5^{+}$ & $4.9(3.6-5.8)$ & $3.7(2.4-5.3)$ & 0.381 \\
\hline $\mathrm{CD}^{+} / \mathrm{DR}^{+}$ & $1.4(0.7-2.8)$ & $4.0(1.1-7.0)$ & 0.068 \\
\hline $\mathrm{CD}^{+} / \mathrm{CD}^{+}$ & 48.7 (39.1-57.1) & $49.1(34.1-52.0)$ & 0.446 \\
\hline $\mathrm{CD}^{+} / 45 \mathrm{RA}^{+}$ & $8.5(2.7-11.0)$ & $2.6(1.3-5.7)$ & 0.007 \\
\hline $\mathrm{CD}^{+} / 45 \mathrm{RO}^{+}$ & $30.6(19.2-34.2)$ & 37.7 (25.3-45.1) & 0.013 \\
\hline $\mathrm{CD}^{+}$ & $21.1(15.7-24.8)$ & $30.0(20.3-36.6)$ & 0.033 \\
\hline $\mathrm{CD}^{+} / \mathrm{CD}^{+}$ & 19.1(17.1-20.8) & $28.7(16.8-33.2)$ & 0.012 \\
\hline $\mathrm{CD}^{-} / 8^{+}$ & $2.9(1.2-6.5)$ & $3.9(3.0-4.9)$ & 0.205 \\
\hline $\mathrm{CD}^{+} / \mathrm{DR}^{+}$ & $0.6(0.3-1.4)$ & $2.3(0.7-5.3)$ & $<0.001$ \\
\hline $\mathrm{CD}^{+} / \mathrm{CDa}^{+}$ & $25.6(8.8$ & $37.4(19.9-52.6)$ & 0.065 \\
\hline $\mathrm{CD}^{+} / \mathrm{CD} \gamma \delta^{+}$ & $0.5(0.2-2.5)$ & $0.4(02-0.8)$ & 0.698 \\
\hline $\mathrm{CD}^{+} / \mathrm{CD} 57^{+}$ & $3.8(2.7-6.9)$ & $1.3(0.5-8.1)$ & 0.235 \\
\hline $\mathrm{CD}_{19}{ }^{+}$ & $10.6(7.8-16.7)$ & $6.8(4.1-8.6)$ & 0.009 \\
\hline
\end{tabular}

Table 3. Expression of membrane molecules on the NK cell subsets

\begin{tabular}{|c|c|c|c|}
\hline Cell population & $\begin{array}{l}\text { Peripheral blood } \\
\text { (\%) }\end{array}$ & $\begin{array}{l}\text { Ascites } \\
\text { (\%) }\end{array}$ & Significance \\
\hline $\mathrm{CD}^{-} / \mathrm{CD}_{16}+\mathrm{CD}^{2} 6^{+}$ & $5.6(2.7-10.7)$ & $11.0(7.1-12.5)$ & 0.041 \\
\hline $\mathrm{CD}^{+} / \mathrm{CD} 16^{+} / \mathrm{CD} 56^{+}$ & $5.5(1.2-7.2)$ & $3.1(0.6-4.8)$ & 0.080 \\
\hline $\mathrm{CD}^{-} / \mathrm{CD}^{-} 6^{+}$ & $11.7(7.7-13.8)$ & $12.9(5.1-15.5)$ & n.s. \\
\hline $\mathrm{CD}^{-} / \mathrm{CD} 16^{+}$ & $8.2(3.1-12.5)$ & $12.1(7.8-15.1)$ & 0.036 \\
\hline $\mathrm{CD}^{6} 6^{-} / \mathrm{CD}_{16} 6^{+}$ & $2.1(0.6-4.8)$ & $1.5(0.2-3.9)$ & n.s. \\
\hline CD56bright & $2.5(1.9-7.4)$ & $10.3(7.0-25.65)$ & $<0.001$ \\
\hline CD56bright from CD56 ${ }^{+}$ & $45.9(31.5-73.5)$ & $83.2(53.7-92.4)$ & $<0.001$ \\
\hline CD56bright 16- & $1.9(0.9-5.8)$ & $8.25(3.8-16.3)$ & $<0.001$ \\
\hline CD56dim $16^{+}$ & $4.4(1.4-7.8)$ & $1.7(0.6-6.9)$ & 0.021 \\
\hline NKG2D+ ${ }^{+}$ & $32.3(25.2-37.6)$ & $45.05(30.9-58.1)$ & 0.034 \\
\hline NKG2D+ from $\mathrm{CD}^{+} 6^{+}$ & 89.9 (85.0-93.1) & $91.0(86.5-95.0)$ & n.s. \\
\hline $\mathrm{CD}^{+} / \mathrm{CD} 56^{+}$ & $5.8(3.2-9.5)$ & $7.7(3.75-10.55)$ & n.s. \\
\hline
\end{tabular}

n.S. - not significant

significantly higher in ascites $(p=0.033)$. The CD8 $8^{+}$population was predominantly composed of $\mathrm{CD}^{+} / 8^{+} \mathrm{T}$ cells, which was significantly higher in ascites $(p=0.012)$. The number of $\mathrm{CD}^{+} / \mathrm{DR}^{+}$lymphocytes was higher in ascites $(p<0.001)$. The relative count of $\mathrm{CD}^{+} \mathrm{T}$ lymphocytes did not differ in between the two compartments. The number of B lymphocytes CD19+ was significantly higher in peripheral blood $(p=0.009)$. The results of the analysis are presented in Table 2.
The results of NK cell analysis are presented in Table 3. Under physiological conditions, NK lymphocytes represent 10-15\% of the lymphocytic population [14]. In patients with advanced EOC, counts of NK cells in peripheral blood (5.6\%) were significantly lower $(p=0.041)$ than those in ascites (11.0\%). In both samples, NK cells were gated from the mononuclear $\mathrm{CD}_{4} 5^{+} / \mathrm{CD}^{-}$population. The CD$56^{\text {bright }}$ subpopulation was determined in the lymphocyte and NK cell population. In both cases, significantly high- 

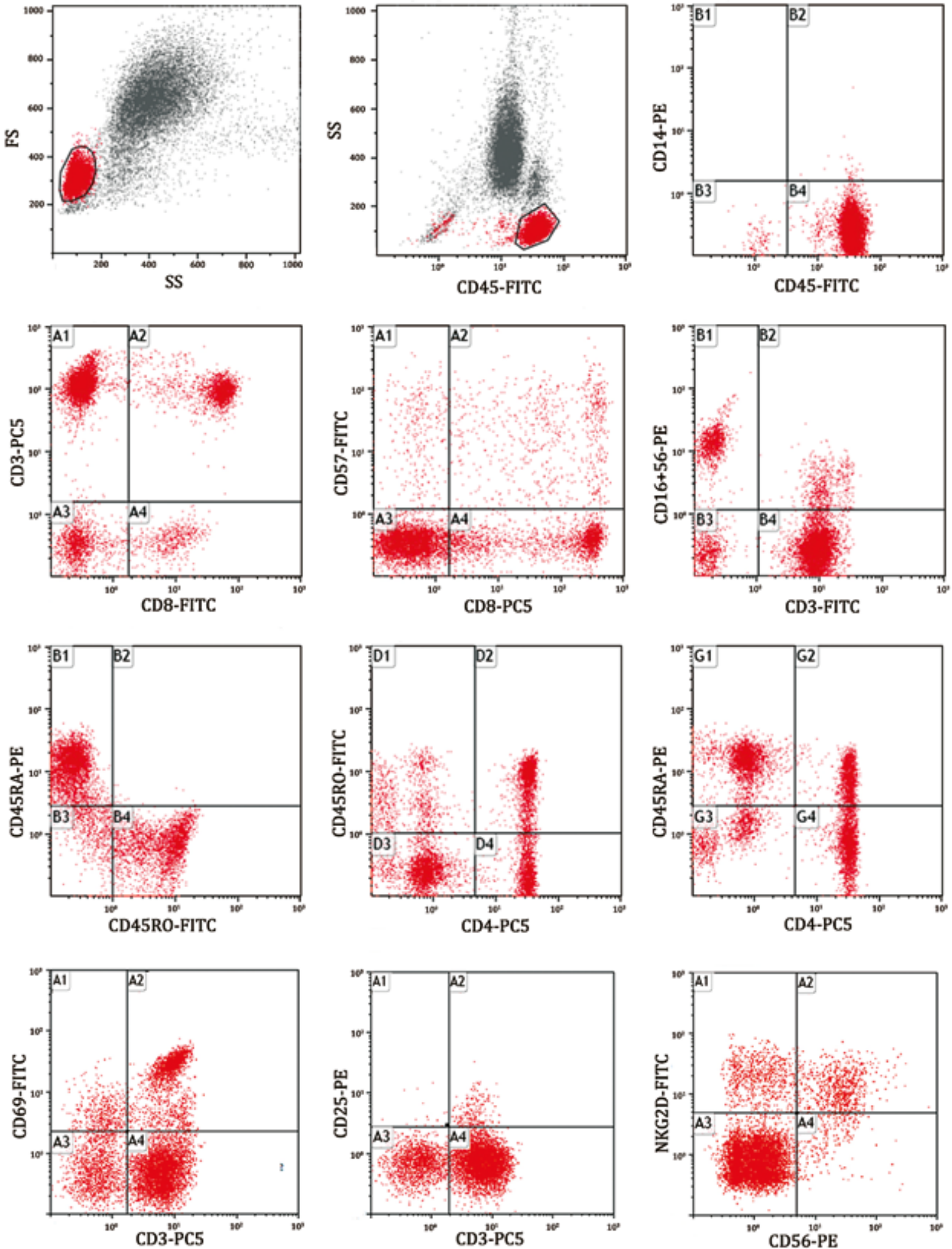

Fig. 1. Representative dot plots gating for ascitic fluid and peripheral blood; identification of cell populations and expression of various markers from $\mathrm{CD}^{+} 5^{+}$cells. (A) Side Scatter (SS) vs. Forward Scatter (FS) plot for identification of leukocytes; (B) Identification of CD45 lymphocytes; and (C) identification of CD45+CD14- lymphocytes; (D-K) Representative dot plots for each monoclonal antibody used in study

er representation of CD56 $6^{\text {bright }}$ NK cells was ascertained in the ascitic fluid. In contrast, the representation of CD56 $6^{\text {dim }}$ $\mathrm{CD}^{+}{ }^{+}$NK cells was significantly higher in peripheral blood. No differences were found in the expression of the natu- ral-killer group 2, member D (NKG2D) activation receptor in the population of NK cells; a significantly higher count of lymphocytes isolated from ascites was expressed by the NKG2D receptor $(p=0.034)$. 
Table 4. Influence of various immunological cells in ascitic fluids on time to first progression using multivariate model with coefficient of determination of 0.49 with a significance level of $p<0.007$

\begin{tabular}{|c|c|c|c|}
\hline & HR & $95 \% \mathrm{Cl}$ & $p$ \\
\hline $\mathrm{CD} 4{ }^{+} \mathrm{RO}$ & 0.996 & 0.911-1.089 & 0.933 \\
\hline $\mathrm{CD} 4^{+} \mathrm{RA}$ & 1.098 & $0.912-1.323$ & 0.314 \\
\hline $\mathrm{CD}^{+}{ }^{+} \mathrm{CD}_{69}{ }^{+}$ & 0.986 & $0.896-1.085$ & 0.771 \\
\hline $\mathrm{CD}^{+} \mathrm{CD}^{+} 7^{+}$ & 1.157 & $0.796-1.682$ & 0.448 \\
\hline $\mathrm{CD}^{+} \mathrm{CD}^{2} 5^{+}$ & 1.288 & $0.903-1.837$ & 0.156 \\
\hline $\mathrm{CD} 8{ }^{+} \mathrm{DR}^{+}$ & 0.869 & $0.371-2.037$ & 0.748 \\
\hline $\mathrm{CD}^{+}{ }^{+} \mathrm{DR}^{+}$ & 1.057 & $0.510-2.192$ & 0.882 \\
\hline $\mathrm{CD}^{+}{ }^{+} \mathrm{CD} 16^{+} \mathrm{CD} 6^{+}$ & 0.945 & $0.668-1.337$ & 0.743 \\
\hline $\mathrm{CD}^{-} \mathrm{CD} 16^{+} \mathrm{CD} 56^{+}$ & 0.907 & $0.717-1.147$ & 0.406 \\
\hline $\mathrm{CD} 3 \mathrm{CD}^{+}$ & 1.160 & 0.904-1.489 & 0.256 \\
\hline $\mathrm{CD}^{+} \mathrm{CD}^{+}$ & 1.011 & $0.900-1.135$ & 0.857 \\
\hline $\mathrm{CD}_{19}+$ & 1.085 & $0.943-1.248$ & 0.239 \\
\hline $\mathrm{CD}^{+}+$ & 0.982 & 0.892-1.081 & 0.709 \\
\hline $\mathrm{CD}^{+}$ & 1.016 & 0.930-1.109 & 0.729 \\
\hline $\mathrm{CD}^{+}$ & 1.060 & $0.957-1.174$ & 0.264 \\
\hline
\end{tabular}

The influence of various immunological cells in ascitic fluid on overall survival was calculated with a multivariate model using a coefficient of determination of 0.65 with a significance level of $p<0.001$. The presence of lymphocytes with the surface marker CD4 in ascitic fluid led to an increased risk of death with a hazard ratio (HR) of 1.2127 (95\% Cl: 1.0384-1.4162). When all the lymphocyte subsets were examined, we found that the presence of $\mathrm{CD}^{-} / \mathrm{CD} 6^{+} / \mathrm{CD}_{5} 6^{+}$and $\mathrm{CD} 43^{+} / \mathrm{CD}^{+}$lymphocytes in ascetic fluid indicated a reduced risk of death with an $\mathrm{HR}$ of 0.6917 (95\% Cl: $0.5434-0.8804)$ and 0.8449 (95\% Cl: 0.7534-0.9587), respectively. But in the case of CD3-/CD8 ${ }^{+}$ and $\mathrm{CD}^{+} / \mathrm{CD} 6^{+} / \mathrm{CD} 6^{+}$lymphocytes, the trend was reversed, with an HR of 1.3139 (95\% Cl: 1.010-1.6909) and 1.3350 (95\% Cl: 1.0788-1.6520), respectively. For other cell subsets no impact on survival was found.

In the case of the impact of the observed immunological cells in ascetic fluid on time to the first progression, we did not observe any correlation or impact.

\section{Discussion}

Ascites in cancer patients can reflect different pathogenic mechanisms of development. Peritoneal carcinomatosis is the most common cause of malignancy-related ascites, followed by massive liver metastases and the obstruction of lymph nodes and vessels. Lymphocytes present in the ascites were consistently referred to as TILS. In the case of malignancy-related ascites not associated with peritoneal carcinomatosis, the term "tumour-associated
Table 5. Influence of various immunological cells in ascitic fluids on overall survival using multivariate model with coefficient of determination of 0.65 with a significance level of $p<0.001$

\begin{tabular}{|c|c|c|c|}
\hline & HR & $95 \% \mathrm{Cl}$ & $p$ \\
\hline $\mathrm{CD} 4{ }^{+} \mathrm{RO}$ & 0.954 & $0.877-1.037$ & 0.272 \\
\hline $\mathrm{CD} 4+\mathrm{RA}$ & 1.037 & $0.924-1.164$ & 0.539 \\
\hline $\mathrm{CD}^{+}{ }^{+} \mathrm{CD}_{69}{ }^{+}$ & 1.074 & $0.967-1.193$ & 0.173 \\
\hline $\mathrm{CD}^{+} \mathrm{CD} 7^{+}$ & 1.092 & $0.789-1.153$ & 0.596 \\
\hline $\mathrm{CD}^{+}{ }^{+} \mathrm{CD} 25^{+}$ & 0.848 & $0.603-1.192$ & 0.330 \\
\hline $\mathrm{CD}^{+} \mathrm{DR}^{+}$ & 0.897 & $0.332-2.424$ & 0.830 \\
\hline $\mathrm{CD}^{+} \mathrm{DR}^{+}$ & 1.066 & $0.472-2.411$ & 0.878 \\
\hline $\mathrm{CD}^{+}{ }^{+} \mathrm{CD} 16^{+} \mathrm{CD} 6^{+}$ & 1.335 & $1.079-1.652$ & 0.014 \\
\hline $\mathrm{CD}^{-} \mathrm{CD}^{-} 6^{+} \mathrm{CD} 56^{+}$ & 0.692 & $0.543-0.880$ & 0.003 \\
\hline $\mathrm{CD}^{-} \mathrm{CD}^{+}$ & 1.314 & $1.021-1.691$ & 0.044 \\
\hline $\mathrm{CD}^{+} \mathrm{CD}^{+}$ & 0.850 & $0.753-0.959$ & 0.002 \\
\hline $\mathrm{CD} 9^{+}$ & 1.085 & $0.947-1.243$ & 0.225 \\
\hline $\mathrm{CD}^{+}$ & 1.021 & $0.927-1.123$ & 0.674 \\
\hline $\mathrm{CD}^{+}$ & 1.213 & $1.038-1.416$ & 0.010 \\
\hline $\mathrm{CD}^{+}$ & 1.000 & 0.895-1.119 & 0.995 \\
\hline
\end{tabular}

lymphocytes" (TALS) is much more suitable. Unfortunately, in individual cases it is difficult to identify prevailing mechanisms of ascites formation. The progression of cancer in the peritoneal cavity and the frequent formation of ascites, which characterize the advanced stage of ovarian cancer, make this tumour a model for the study of different lymphocytic populations [15].

Studies comparing the representation of cellular populations in tumour-induced ascites fluid with findings of ascites for other reasons can be reproduced and interpreted only with difficulty because no "normal" ascites exist. It is always a pathologic finding induced by some of the above-mentioned mechanisms that possesses an inflammatory component of various intensity, e.g. cirrhosis [16, 17].

The presence of tumour-infiltrating lymphocytes in the EOC stroma is important in terms of prognosis, which is confirmed by the outcomes of numerous studies [19, 20]. In our study, obtained data from Cox proportional-hazards regression describing the relationship between each immunological cellular subset and overall survival or time to progression needs to be interpreted with caution due to the heterogeneity of the studied population. But it shows that the presence of NK cells and cytotoxic T cells in ascitic fluid may play a positive role.

$\mathrm{CD}^{+} \mathrm{T}$ lymphocytes are the main cellular population situated at the site of the tumour as well as peripheral blood. The number of $\mathrm{CD}^{+} \mathrm{CD}^{+}$lymphocytes dominated the $\mathrm{CD}^{+} / \mathrm{CD}^{+}$lymphocytes and did not differ between the two compartments studied. This result is in compliance with a study by Bamias et al.; nevertheless, in the case of 


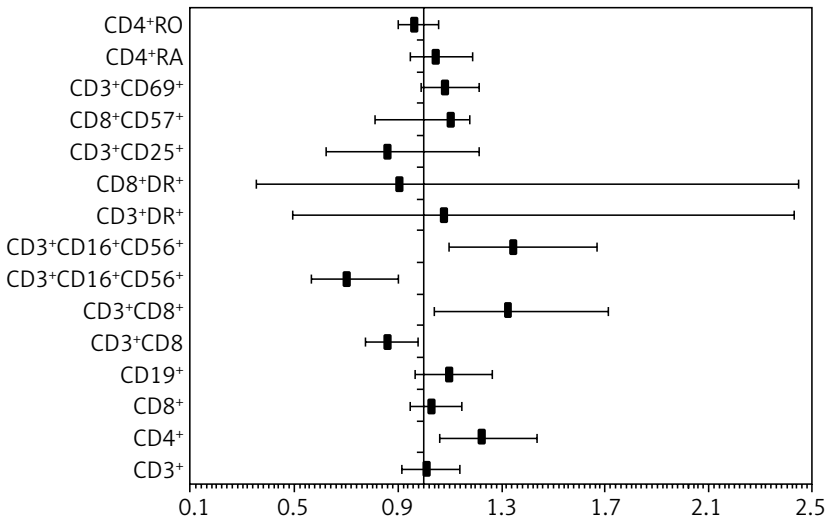

Fig. 2. Potential effect of various immunocompetent cells from ascitic fluid on overall survival calculated using Cox proportional-hazards regression model

tumours of another origin, for instance a non-small-cell lung carcinoma or renal carcinoma, the representation of CD4 ${ }^{+}$and $C D 8^{+}$lymphocytic subpopulations was different $[17,19,21]$. The number of $\mathrm{CD}^{+} / \mathrm{CD} 45 \mathrm{RO}^{+}$lymphocytes in the ascites of our patients was significantly higher than in peripheral blood. Also, the ratio of $\mathrm{CD}^{+} \mathrm{T}$ lymphocytes which had undergone rearrangement of gene segments for TcR $\left(C D 45 R O^{+}\right)$to naïve (CD45RA+) was higher in ascites. This finding can be considered proof of the activation of a specific cellular anti-tumour response [19]. CD4 ${ }^{+} T$ lymphocytes play an ambivalent role in the anti-tumour response. The cytotoxic anti-tumour response is ensured by the Th1 subset, whereas the prevailing function of the Th2 subset is accompanied by the progression of tumours. The immune response of both Th1 and Th2 is accompanied by production of the following cytokines: interleukin-2 (IL-2), IL-12, interferon $\gamma$ (IFN- $\gamma$ ), tumor necrosis factor $\alpha$ (TNF- $\alpha$ ) (Th1 response), IL-3, IL-4, IL-10 and IL-13 (Th2 response) $[22,23]$. In ascites, these cytokines can also be produced by tumour cells, and together with chemokines they are involved in the formation of a gradient determining the migration and function of leukocytes [24]. Despite the fact that the prognostic role of individual cytokines in tumours has been studied on a long-term basis, no explicit answer can be given to this question. An idea predominates in which cytokines strengthening the Th1 response are considered favourable in terms of prognosis [24].

The cytotoxic reaction as ensured by cytotoxic $C D 8^{+} \mathrm{T}$ lymphocytes and NK cells is crucial for the achievement of an effective anti-tumour response. In the majority of $\mathrm{CD}^{+}$ and $C D 8^{+} T$ lymphocytes, the receptor for antigen (TCR) is created by the $\alpha \beta$ heterodimer, and the relationship between TcR $\alpha \beta$ and TcR $\gamma \delta$ lymphocytes is the same both in the peripheral blood and in ascites $[25,26]$. Our findings, along with those from experimental studies, have indicated that the specific anti-tumour response is not restricted by the TCR type $[27,28]$. The relative count of $\mathrm{CD}^{+} / 8^{+}$lymphocytes was significantly higher in ascites. Under physiological conditions, the $\mathrm{CD}^{+}$population expressing the CD56 and CD57 molecule (NK type of T lymphocytes) is a minori-

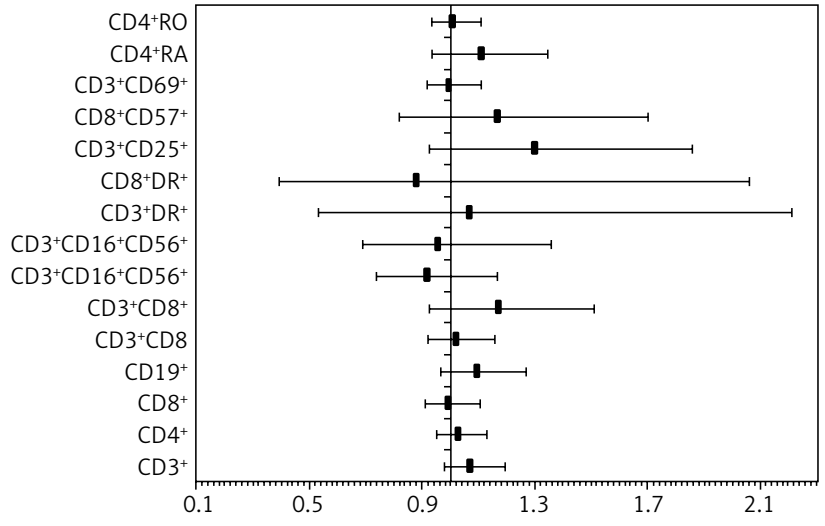

Fig. 3. Potential effect of various immunocompetent cells from ascitic fluid on length of time to first progression calculated using Cox proportional-hazards regression model

ty population in peripheral blood; however, its presence is higher in lymphatic nodes, the spleen and bone marrow. The NK type $\mathrm{CD}^{+}$of lymphocytes exhibits an oligoclonal expansion $V \beta$ of the TCR chain different from other $C D 8^{+} T$ lymphocytes after antigenic stimulation. Based on this fact, $\mathrm{CD}_{56}{ }^{+}$and $\mathrm{CD} 57^{+} \mathrm{T}$ lymphocytes are considered an independent population of cytotoxic lymphocytes. Their role is not known precisely, however [29, 30]. These lymphocytes of $\mathrm{CD}^{+} \mathrm{NK}$ type produce IFN- $\gamma$ more intensively than $\mathrm{CD}^{+}$ T lymphocytes [31]. The count of $\mathrm{CD}^{+} / 57^{+}$cytotoxic lymphocytes, although not achieving significance, was lower in the ascitic fluid of our patients than in their peripheral blood. Such a reduction can be caused both by insufficient proactivation and strengthened inhibition signals and, subsequently, by an enhanced switch of activated cytotoxic cells into apoptosis [29]. The switch of stimulated cells into apoptosis takes place in the absence of accessory intercellular bindings, but apoptosis can also be induced by soluble factors from the family of TNF proteins produced by cells of the tumour stroma, mainly macrophages associated with the tumour [32-34]. Activated T lymphocytes express CD 69 and HLA-DR membrane molecules. The early activation antigen CD69 belongs to the superfamily of C-type lectin. Following activation of $\mathrm{T}$ lymphocytes, it is one of the first proteins expressed within the membrane. It is involved in strengthening intercellular interactions as a co-stimulation molecule. The CD69 molecule is not line-specific and is also situated on other blood cells [35]. The finding of a significantly higher representation of $\mathrm{CD}^{+} / \mathrm{CD} 69^{+}$cells in the ascites than in peripheral blood indicates a stimulation of $\mathrm{T}$ lymphocytes in which the cytokine/chemokine microenvironment is also involved together with tumour antigens. The enhanced representation of $\mathrm{CD}^{+} / \mathrm{DR}^{+}$lymphocytes in ascites did not reach statistical significance in our patients compared to peripheral blood, but it exhibited a similar trend as mentioned in the paper by Bamias et al., who observed a significantly higher representation of CD4+/HLADR and $\mathrm{CD}^{+} / \mathrm{HLADR}$ of $\mathrm{T}$ lymphocytes in ascites [17].

The $\mathrm{CD}^{+} / \mathrm{CD}_{25} 5^{+}$population of lymphocytes was considered proof of the alpha-chain expression for IL-2 on T lym- 
phocytes; its representation in ascites was lower than that in $\mathrm{PB}$, but the difference was not significant. This phenotype of $T$ lymphocytes includes the $\mathrm{CD} 4^{+} / \mathrm{CD} 25^{+}$subpopulation expressing the FoxP3 molecule identified as the regulatory T lymphocytes (Tregs) [13]. The presence of Tregs in the EOC stroma is considered as an unfavourable finding in terms of prognosis, associated with a shorter length of overall survival. A higher representation of $\mathrm{CD} 4^{+} / \mathrm{CD} 25^{+}$ lymphocytes was described in malignant ascites than in non-malignant ones and was higher in the tumour stroma than in draining nodes [36, 37]. Therefore, the finding of a higher number of $\mathrm{CD}^{+} / \mathrm{CD} 25^{+}$lymphocytes in the peripheral blood of our female EOC patients was surprising to us, and we are going to subject it to further analysis.

The precise role of $\mathrm{B}$ lymphocytes in the anti-tumour response is not known. Their presence in the tumour stroma confirms their involvement in the anti-tumour response [38]. In the case of tumours, the antibody response to tumour antigens after lg binding can lead to blockage of epitopes distinguished by specific cytotoxic T lymphocytes, and the tumour growth can be potentiated. Higher occurrence of B lymphocytes among TILs was observed in patients with prevailing activity of $\mathrm{CD}^{+}$infiltrating lymphocytes, respectively the Th2 population. The significance of the role of the antigen-presenting cell has not been explicitly demonstrated in the case of B lymphocytes in tumour diseases [39-43]. In our patients, the incidence of B lymphocytes in ascites was significantly lower than that in peripheral blood.

NK cells constituting an important component of the natural immunity play an essential role in the anti-tumour response. They are a significant producer of IFN- $\gamma$ and TNF- $\alpha$. Activation of NK cells and the cytotoxic response are not dependent on the preceding sensitization [44]. In experimental studies, NK cells exhibited cytotoxicity targeted against EOC cells after IL-2 activation. In the case of EOC, the expression of mucin molecules (MUC) on tumour cells is important [45]. In particular, the presence of MUC16, the carrier for the CA125 tumour marker, is able to inhibit an efficient cytotoxic reaction as mediated by NK cells [6]. In compliance with data from literature resources, significantly higher counts of CD56 bright NK cells in ascites were also found in EOC patients' ascites in our case [46]. Such a finding can be caused by blockage of the lymphatic drainage on suppression induced by the expanding tumour. Even under physiological conditions, lymphatic nodes can contain up to $95 \%$ of CD56 bright NK cells [47]. Selective uptake of CD56 bright NK cells by the CD62L molecule expressed on NK cells in lymphatic nodes can be another mode of action. Based on the latest studies, it is understood that CD56 $6^{\mathrm{dim}}$ and CD56 $6^{\text {bright }}$ cells represent various differentiation stages of NK lymphocytes, with the CD56 dim cells representing a more mature type [48]. It is impossible to exclude the possibility that maturation of NK cells is blocked after encountering tumour antigens. This possibility follows from experimental observations where MUC16 positive tumour cells inhibited expression of the CD16 molecule on NK cells from healthy donors [49]. The cytotoxic activity of CD56 bright CD16- NK cells is lower, although granules containing perforins and granzymes are abundantly present in cytoplasm [50]. The situation when the CD16- cells accounted for more than $75 \%$ of CD56 bright ascitic NK cells in our female patients can be considered a manifestation of the inhibited NK-mediated cytotoxicity.

NKG2D is a type II trans-membrane-anchored C-type lectin-like receptor. In the homodimer form it can be found not only on NK cells but also on NKT cells, CD8 ${ }^{+}$cytotoxic $T$ cells and $\gamma \delta T$ cells, and it has also been described on $\mathrm{CD}^{+} \mathrm{T}$ lymphocytes. It is a highly evolutionary conserved receptor that distinguishes ligands exhibiting homology with class I MHC molecules [51]. A short intracellular section of the NKG2D receptor has no signal motif; it is associated with other signal-transducing proteins in the trans-membrane section [52]. In addition, two isoforms of NKG2D have been described, which differ by the presence or absence of 13 amino acids in the $\mathrm{N}$ end of the cytoplasmic part of the molecule. The long NKG2D isoform binds exclusively with DAP10 adapter protein and recruits phosphoinositide kinase-3 (PI3K) and growth factor receptor-bound proteins 2 (Grb2) by means of YINM. The short NKG2D isoform is associated both with DAP10 and the DAP12 signal-transducing protein [53]. The cytoplasmic part of the DAP12 protein carries the immunoreceptor tyrosine-based activation motif (ITAM) phosphorylation, which leads to involvement of the zeta-chain-associated protein kinase 70 (Zap70) and spleen tyrosine kinase (Syk) signal cascade. Each NKG2D homodimer is associated with two DAP10 and DAP12 homodimers. It is not known whether DAP10 and DAP12 can be simultaneously contained in the hexameric receptor complex; this would, however, lead to a marked amplification of signal paths $[54,55]$.

A higher NKG2D positive lymphocyte count was found in the ascites of EOC patients than in peripheral blood, with this count being at the level of significance. Nevertheless, the lymphocytic population studied also included B lymphocytes, which do not express the CD94 and CD4 ${ }^{+}$ molecule $T$ lymphocytes, in which only a minority population is NKG2D positive. This fact is also confirmed by NKG2D expression on NK cells of ascites and PB when the two compartments exhibited identical relative representation of positive cells. In practice, it is impossible to assess the function of NK cells according to the expression of activation molecules because these molecules are also expressed on cells at peace under physiological conditions [56]. The NK cell function is regulated by the balance of signals from activation and inhibition receptors. Inhibition signals are mediated mainly by receptors binding HLA I molecules, including killer cell Ig-like receptors (KIRs) such as NKG2A and leukocyte Ig-like receptor B1 (LILR-B1) [57]. Signals coming by means of NKG2C, NKG2D, DNAX accessory molecule-1 (DNAM-1) receptors and natural cytotoxic receptors (NKp30, NKp44 and NKp46) are responsible for the activation. The CD16 molecule mediates Ab-dependent cellular cytotoxicity. The function of the co-stimulation of LFA-1 and 2B4 molecules is also important. The combination of activation and inhibition signals is decisive for the function of NK cells [58].

Although our quantitative analysis showed similarities with previous studies [24, 43], the aforesaid data, as well as our findings, have confirmed the present idea of EOC 
cells and cells of other tumours affecting both the expression of membrane receptors of cytotoxic cells and the expression of their ligands, whether directly or by means of soluble mediators. The combination of chemotherapy and immunotherapy is still under consideration, and therefore molecules such as NKG2D still remain at the centre of interest. Although treatment using recombinant IFN- $\alpha$ and IFN- $\gamma$ in clinical practice leads to strengthening of the NKG2D expression on cytotoxic cells, at the same time downregulation of its HP60 ligand takes place on sarcoma cells, or of the MICA ligand on melanoma cells, thereby facilitating their evasion [56, 59]. Results of experimental studies in experimental animals, in which a strengthened cytotoxic effect of molecularly/genetically modified cytotoxic lymphocytes expressing the chimeric NKG2D on tumour cells, leading to long-term tumour-free survival, was observed, have been published $[60,61]$. The modification of the anti-tumour response of natural-immunity mechanisms remains one of the most promising ways of treating tumours. But many more functional studies are still necessary in order to determine the role of each immunocompetent cell population in ovarian cancer.

This study has been supported by the research programme PRVOUK P37.

The authors declare no conflict of interest.

\section{References}

1. Jemal A, Siegel R, Ward E, Hao Y, Xu J, Thun MJ. Cancer statistics 2009. CA Cancer J Clin 2009; 59: 225-49.

2. Miedzinska-Maciejewska M, Wcislo G, Bodnar L. The modulation of multidrug resistance in ovarian cancer patiens. Współcz Onkol 2004; 8: 457-65.

3. Sikora J. The role of TCR $\zeta$ expression in immunosuppression induced by tumour. Współcz Onkol 2009; 13: 457-65.

4. Freedman RS, Kudelka AP, Kavanagh JJ, et al. Differential expression of CD3zeta message and protein in tumor infiltrating lymphocytes from solid tumor specimens and malignant ascites from patients with ovarian carcinoma. Clin Cancer Res 2000; 6: 2268-78.

5. Cózar JM, Canton J, Tallada M, Concha A, Cabrera T, Garrido F, Ruiz-Cabello Osuna F. Analysis of NK cells and chemokine receptors in tumor infiltrating CD4 T lymphocytes in human renal carcinomas. Cancer Immunol Immunother 2005; 54: 858-66.

6. Gavalas NG, Karadimou A, Dimopoulos MA, Bamias A. Immune Response in Ovarian Cancer: How Is the Immune System Involved in Prognosis and Therapy: Potential for Treatment Utilization. Clin Dev Immunol 2010; 2010: 791603, doi: 10.1155/2010/791603.

7. Zamarron BF, Chen W. Dual roles of immune cells and their factors in cancer development and progression. Int J Biol Sci 2011; 7: 651-8.

8. Garrido F, Ruiz-Cabello F, Cabrera T, Pérez-Villar JJ, López-Botet M, Duggan-Keen M, Stern PL. Implications for immunosurveillance of altered HLA class I phenotypes in human tumours. Immunol Today 1997; 18: 89-95.

9. Maleno I, Cabrera CM, Cabrera T, Paco L, López-Nevot MA, Collado A, Ferrón A, Garrido F. Distribution of HLA class I altered phenotypes in colorectal carcinomas: high frequency of HLA haplotype loss associated with loss of heterozygosity in chromosome region 6p21. Immunogenetics 2004; 56: 244-53.

10. Marincola FM, Jaffee EM, Hicklin DJ, Ferrone S. Escape of human solid tumors from T-cell recognition: molecular mechanisms and functional significance. Adv Immunol 2000; 74: 181-273.
11. Ishigami S, Natsugoe S, Tokuda K, et al. Clinical impact of intratumoral natural killer cell and dendritic cell infiltration in gastric cancer. Cancer Lett 2000; 159: 103-8.

12. Curiel TJ, Coukos G, Zou L, et al. Specific recruitment of regulatory $T$ cells in ovarian carcinoma fosters immune privilege and predicts reduced survival. Nat Med 2004; 10: 942-9.

13. Sato E, Olson SH, Ahn J, et al. Intraepithelial CD8-tumor-infiltrating lymphocytes and a high CD8-regulatory $T$ cell ratio are associated with favorable prognosis in ovarian cancer. Proc Natl Acad Sci U S A 2005; 102: 18538-43.

14. Belisle JA, Gubbels JA, Raphael CA, Migneault M, Rancourt C, Connor JP, Patankar MS. Peritoneal natural killer cells from epithelial ovarian cancer patients show an altered phenotype and bind to the tumour marker MUC16 (CA125). Immunology 2007; 122: 418-29.

15. Markman M, Markman J, Webster K, Zanotti K, Kulp B, Peterson B, Belinson J. Duration of response to second-line, platinum-based chemotherapy for ovarian cancer: implications for patient management and clinical trial design. J Clin Oncol 2004; 22: 3120-5.

16. Kryczek I, Liu R, Wang G, et al. FOXP3 defines regulatory T cells in human tumor and autoimmune disease. Cancer Res 2009; 69: 3995-4000.

17. Bamias A, Tsiatas ML, Kafantari E, et al. Significant differences of lymphocytes isolated from ascites of patients with ovarian cancer compared to blood and tumor lymphocytes. Association of CD3+CD56+ cells with platinum resistance. Gynecol Oncol 2007; 106: $75-81$.

18. Tsiatas ML, Gyftaki R, Liacos C, Politi E, Rodolakis A, Dimopoulos MA, Bamias A. Study of T lymphocytes infiltrating peritoneal metastases in advanced ovarian cancer: associations with vascular endothelial growth factor levels and prognosis in patients receiving platinum-based chemotherapy. Int J Gynecol Cancer 2009; 19: 1329-34.

19. Leffers N, Gooden MJ, de Jong RA, et al. Prognostic significance of tumor-infiltrating T-lymphocytes in primary and metastatic lesions of advanced stage ovarian cancer. Cancer Immunol Immunother 2009; 58: 449-59.

20. Vermeij R, de Bock GH, Leffers N, et al. Tumor-infiltrating cytotoxic T lymphocytes as independent prognostic factor in epithelial ovarian cancer with Wilms tumor protein 1 overexpression. J Immunother 2011; 34: 516-23.

21. Wakabayashi O, Yamazaki K, Oizumi S, Hommura F, Kinoshita I, Ogura S, Dosaka-Akita H, Nishimura M. CD4+ T cells in cancer stroma, not CD8+ T cells in cancer cell nests, are associated with favorable prognosis in human non-small cell lung cancers. Cancer Sci 2003; 94: 1003-9.

22. Kim R, Emi M, Tanabe K. Cancer immunosuppression and autoimmune disease: beyond immunosuppressive networks for tumour immunity. Immunology 2006; 119: 254-64

23. Chen LL, Ye F, Lü WG, Yu Y, Chen HZ, Xie X. Evaluation of immune in hibitory cytokine profiles in epithelial ovarian carcinoma. J Obstet Gynaecol Res 2009; 35: 212-8.

24. Milliken D, Scotton C, Raju S, Balkwill F, Wilson J. Analysis of chemokines and chemokine receptor expression in ovarian cancer ascites. Clin Cancer Res 2002; 8:1108-14.

25. Horalka K, Miyamoto M, Cho Y, et al. Concurrent infiltration by CD8+ T cells and CD4+ T cells is a favourable prognostic factor in non-small-cell lung carcinoma. Br J Cancer 2006; 94: 275-80.

26. Tomšová M, Melichar B, Sedláková I, Steiner I. Prognostic significance of CD3+ tumor-infiltrating lymphocytes in ovarian carcinoma. Gynecol Oncol 2008; 108: 415-20.

27. Girardi M, Glusac E, Filler RB, Roberts SJ, Propperova I, Lewis J, Tigelaar RE, Hayday AC. The distinct contributions of murine T cell receptor $(T C R) \gamma \delta+$ and TCR $\alpha \beta+$ T cells to different stages of chemically induced skin cancer. J Exp Med 2003; 198: 747-55.

28. Girardi M. Immunosurveillance and Immunoregulation by $\gamma \delta \mathrm{T}$ Cells. J Invest Dermatol 2006; 126: 25-31.

29. Ohkawa T, Seki S, Dobashi H, Koike Y, Habu Y, Ami K, Hiraide H, Sekine I. Systematic characterisation of human CD8+ T cells with natural killer cell markers in comparasion with natural cells and normal CD8+ T cells. Imunology 2001; 103: 281-90.

30. Uhrberg M, Valiante NM, Young NT, Lanier LL, Phillips JH, Parham P. The repertoire of killer cell Ig-like receptor and D94:NKG2A recep- 
tors in T cells: Clones sharing identical $\alpha \beta$ TcR rearrangement express highly diverse killer cell Ig-like receptor patterns J Immunol 2001; 166: 3923-32.

31. Van den Hove LE, Van Gool SW, Vandenberghe P, Boogaerts MA, Ceuppens JL. CD57+/CD28- T cells in untreated hemato-oncological patients are expanded and display a Th1-type cytokine secretion profile, ex vivo cytolytic activity and enhanced tendency to apoptosis. Leukemia 1998; 12: 1573-82.

32. Kraman M, Bambrough PJ, Arnold JN, et al. Suppression of antitumor immunity by stromal cells expressing fibroblast activation protein-alpha. Science 2010; 330: 827-30.

33. Bianchi G, Borgonovo G, Pistoia V, Raffaghello L. Immunosuppressive cells and tumour microenvironment: Focus on mesenchyma stem cells and myeloid derived suppressor cells. Histol Histopathol 2011; 26: 941-51.

34. Lazennec G, Jorgensen Ch. Concise review: adult multipotent stromal cells and cancer: risk or benefit? Stem Cells 2008; 26: 1387-94.

35. Miki-Hosokawa T, Hasegawa A, Iwamura C, et al. CD69 controls the pathogenesis of allergic airway inflammation. J Immunol 2009; 183: 8203-15.

36. Curiel TJ, Coukos G, Zou L, et al. Specific recruitment of regulatory $T$ cells in ovarian carcinoma fosters immune privilege and predicts reduced survival. Nat Med 2004; 10: 942-9.

37. 37. Wolf D, Wolf AM, Rumpold H, et al. The expression of the regulatory $T$ cell-specific forkhead box transcription factor FoxP3 is associated with poor prognosis in ovarian cancer. Clin Cancer Res 2005; 11: 8326-31.

38. Wright SE, Rewers-Felkins KA, Quinlin IS, et al. Cytotoxic T-lymphocyte Immunotherapy for ovaria cancor: A pilot study. J Immunother 2012; 35: 196-204.

39. Linnebacher M. Tumor infiltrating Bcells come into vogue. World J Gastroenterol 2013; 19: 8-11.

40. Nielsen JS, Sahota RA, Milne K, et al. CD20+ tumor-infiltrating lymphocytes have an atypical CD27- memory phenotype and together with CD8+ T cells promote favorable prognosis in ovarian cancer. Clin Cancer Res 2012; 18: 3281-92.

41. Santin AD, Hermonat PL, Ravaggi A, et al. Phenotypic and functional analysis of tumor-infiltrating lymphocytes compared with tumor-associated lymphocytes from ascitic fluid and peripheral blood lymphocytes in patients with advanced ovarian cancer. Gynecol Obstet Incest 2001; 51: 254-61.

42. Papamichail M, Perez SA, Gritzapis AD, Baxevanis CN. Natural killer lymphocytes; biology, development and function. Cancer Immunol Immunother 2004; 53: 176-86.

43. Gubbels JA, Claussen N, Kapur AK, Connor JP, Patankar MS. The detection, treatment, and biology of epithelial ovarian cancer. J Ovarian Res 2010; 29: 8. doi: 10.1186/1757-2215-3-8.

44. Fehniger TA, Cooper MA, Nuovo GJ, Cella M, Facchetti F, Colonna M, Caligiuri MA. CD56 bright natural killer cells are present in human lymph nodes and are activated by T cell-derived IL-2: a potential new link between adaptive and innate immunity. Blood 2003; 101 3052-7.

45. Poli A, Michel T, Thérésine M, Andrès E, Hentges F, Zimmer J. CD56bright natural killer (NK) cells: an important NK cell subset. Imunology 2009; 126: 458-65.

46. 46. Romagnnani C, Juelke K, Falco M, et al. CD56 bright CD16- killer Ig like receptor - NK cells display longer telomeres and acquire feature of CD56 dim NK cells upon activation. J Immunol 2007; 178: 4947-55.

47. Patankar MS, Jing Y, Morrison JC, et al. Potent suppression of natural killer cell response mediated by the ovarian tumor marker CA 125. Gynecol Oncol 2005; 99: 704-13.

48. Jacobs R, Hintzen G, Kemper A, Beul K, Kempf S, Brehrens G, Sykora KW, Schmidt RE. CD56 bright NK cells differ KIR repertoire and cytotoxic features from CD56dim NK cells. Eur J Immunol 2001; 31: 3121-6.

49. McFarland BJ, Kortemme T, Yu SF, Baker D, Strong RK. Symmetry recognizing asymmetry: analysis of the interactions between the C-type lectin-like immunoreceptor NKG2D and MHC class I-like ligands. Structure 2003; 11: 411-22.

50. Houchins JP, Yabe T, McSherry C, Bach FH. DNA sequence analysis of NKG2, a family of related cDNA clones encoding type II integral membrane proteins on human natural killer cells. J Exp Med 1991; 173: $1017-20$

51. Gilfillan S, Ho EL, Cella M, Yokoyama WM, Colonna M. NKG2D recruits two distinct adapters to trigger NK cell activation and costimulation. Nat Immunol 2002; 3: 1150-5.

52. Lanier LL, Corliss BC, Wu J, Leong C, Phillips JH. Immunoreceptor DAP12 bearing a tyrosine-based activation motif is involved in activating NK cells. Nature 1998; 391: 703-7.

53. Garrity D, Call ME, Feng J, Wucherpfennig KW. The activating NKG2D receptor assembles in the membrane with two signaling dimers into a hexameric structure. Proc Natl Acad Sci U S A 2005; 102: 7641-6.

54. Champsaur M, Lanier LL. Effect of NKG2D ligand expression on host immune responses. Immunol Rev 2010; 235: 267-85.

55. Long EO. Negative signaling by inhibitory receptor: the NK cell paradigm. Immunol Rev 2008; 224: 70-84.

56. Carlsten M, Norell H, Bryceson YT, Poschke I, Schedvins K, Ljunggren HK, Kieslling R, Malmberg KJ. Primary human tumor cells expressing CD155 impair tumor targeting by down-regulating DNAM-1 on NK Cells. J Immunol 2009; 183: 4921-30.

57. Bui JD, Carayannopoulos LN, Lanier LL, Yokoyama WM, Schreiber RD. IFN-dependent down-regulation of the NKG2D ligand H60 on tumors. J Immunol 2006; 176: 905-13.

58. Barber A, Sentman CL. Chimeric NKG2D T cells require both $T$ cell- and host-derived cytokine secretion and perforin expression to increase tumor antigen presentation and systemic immunity. J Immunol 2009; 183: 2365-72.

59. Barber A, Rynda A, Sentman CL. Chimeric NKG2D expressing T cells eliminate immunosuppression and activate immunity within the ovarian tumor microenvironment. J Immunol 2009; 183: 6939-47.

\section{Address for correspondence}

\section{Otakar Kopecky}

\section{Department of Oncology}

District Hospital Nachod

Purkynova 446

54769 Nachod

Czech Republic

e-mail: kopecky.otakar@nemocnicenachod.cz

Submitted: 18.06 .2014

Accepted: $\quad 18.03 .2015$ 